\title{
The German Working Group of Obesity in Childhood and Adolescence (AGA): Improving the Quality of Care for Overweight and Obese Children in Germany
}

\author{
Thomas Reinehr ${ }^{\mathrm{a}}$ Reinhard W. Holl ${ }^{\mathrm{b}}$ Martin Wabitsch ${ }^{\mathrm{c}}$ \\ a Vestische Hospital for Children and Adolescents Datteln, University of Witten-Herdecke, \\ ${ }^{\mathrm{b}}$ Institute for Epidemiology, \\ c Pediatric Endocrinology, Department of Pediatrics, University of Ulm, Ulm, Germany
}

\section{Key Words}

Guidelines · Certification · Quality control

\section{Summary}

The Working Group of Obesity in Childhood and Adolescence (AGA) comprises scientists, clinicians, and therapists dealing with obesity in children and adolescents. More than 250 pediatricians, psychiatrics, dieticians, psychologists and sports therapists are integrated. On an international level, the AGA cooperates with the European Childhood Obesity Group and the International Obesity Taskforce (IOTF) for Childhood Obesity. The aims of the AGA are to initiate clinical and scientific studies, to join diagnostic, therapeutic and scientific centers, to improve the education, to support self-help groups, and to standardize diagnostic and therapeutic procedures in the field of obesity in childhood and adolescence. The milestones in the history of the AGA are the consensus process to define overweight and obesity in Germany, the development of guidelines for diagnostic procedures and treatment of obesity in childhood and adolescence, the determination of all therapy centers for obese children and adolescents in Germany, the development of a PC software (APV) to document longitudinally diagnostic and therapeutic procedures as well as outcomes by a quality management program, the certification of therapeutic institutions, and the implementation of prevention and treatment studies. As effect of these initiatives, the quality of care in overweight children has been improved in the last years. For example, the APV quality program demonstrated an increase of diagnostic procedures such as blood pressure measurement in the last 4 years.

\section{Introduction}

The Working Group of Obesity in Childhood and Adolescence (Arbeitsgemeinschaft Adipositas im Kindes- und Jugendalter; AGA) comprises scientists, clinicians, and therapists dealing with obesity in children and adolescents. More than 250 pediatricians, psychiatrics, dieticians, psychologists and sports therapists are integrated. The group was founded in 1998 after the congress of the European Childhood Obesity Group (ECOG). The AGA is a working group of the German Society of Obesity (Deutsche Adipositasgesellschaft; DAG) and of the German Society of Pediatrics (Deutsche Gesellschaft für Kinder- und Jugendmedizin; DGKJ). On an international level, the AGA cooperates with the ECOG and the International Obesity Taskforce (IOTF) for Childhood Obesity (fig. 1).

The aims of the AGA are

- to initiate clinical and scientific projects to i) determine causes of obesity, ii) improve diagnostic procedures, and iii) evaluate prevention and therapeutic concepts,

- to join diagnostic, therapeutic and scientific centers,

- to improve the education,

- to support self-help groups

- to standardize diagnostic and therapeutic procedures,

- to initiate scientific studies, and

- to cooperate with national and international scientific societies.

The milestones in the history of the AGA

(see also www.a-g-a.de) are

- the consensus process to define overweight and obesity in Germany and to study the frequency of overweight in German children and adolescence,

- the guidelines for diagnostic procedures and treatment of obesity in childhood and adolescence based on the AWMF

PD Dr. med. Thomas Reinehr

Vestische Kinder- und Jugendklinik

Universität Witten-Herdecke

Dr. F. Steiner Straße 5, 45711 Datteln, Germany

Tel. +49 2363 975-229, Fax -218

E-mail T.Reinehr@kinderklinik-datteln.de 
Fig. 1. Aims and cooperation of the German Working Group of Obesity in Childhood and Adolescence.

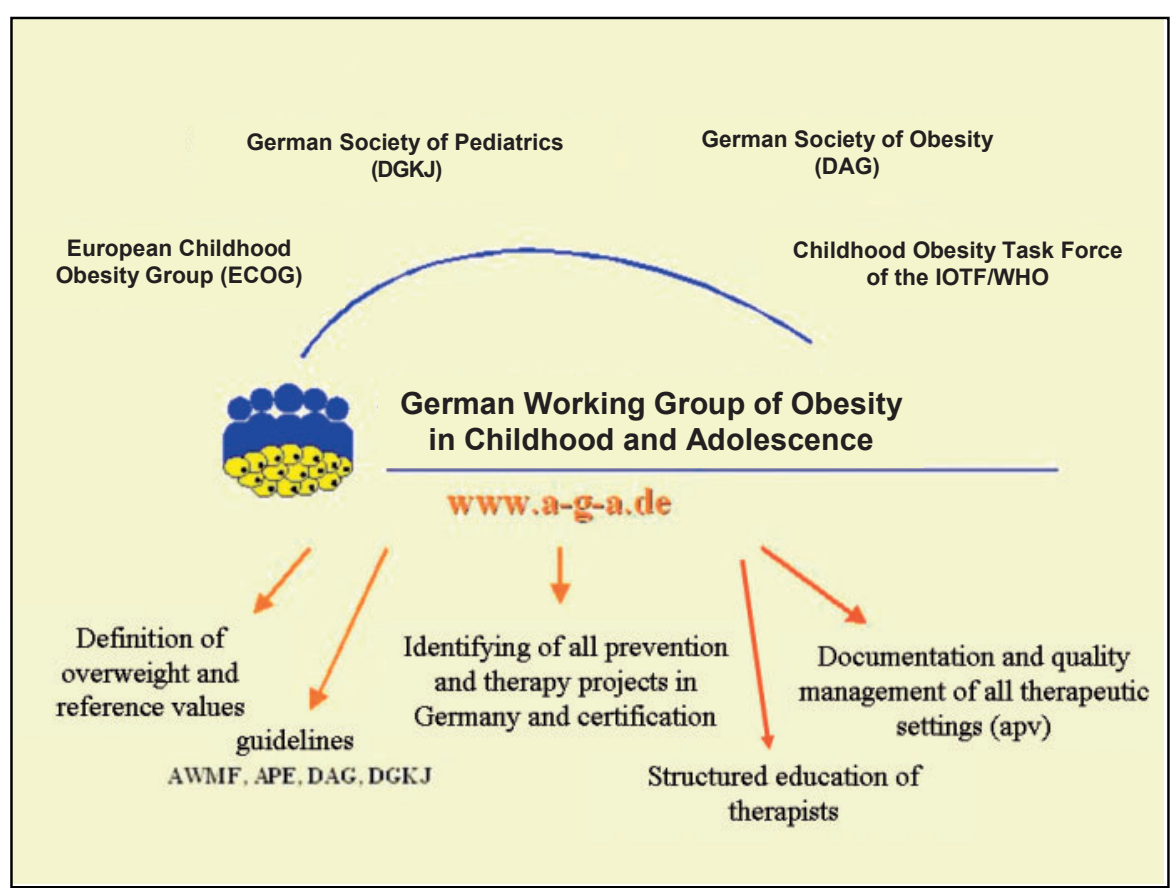

criterions $(\mathrm{AWMF}=$ Arbeitsgemeinschaft der Wissenschaftlichen Medizinischen Fachgesellschaften; Working Committee of the German Scientific Medical Societies),

- the determination of all therapy centers for obese children and adolescents in Germany,

- the development of a PC software (APV) to document longitudinally diagnostic and therapeutic procedures as well as outcomes of care as part of a quality management program.

- the certification of therapeutic institutions based on the national guidelines of health insurances and the German Federal Ministry of Health, and

- the implementation of scientific prevention and treatment studies such as the BZgA Observation Study and the Trink Dich Fit Study.

\section{Definition and Prevalence of Overweight and Obesity in Germany}

The frequency of overweight and obesity is increasing wordwide [1]. Multiple definitions of overweight and obesity are suggested, resulting in considerable difficulty to compare different studies. An international definition of overweight and obesity in childhood and adolescence has been proposed by the IOTF, which is based on percentiles adapted to the definition of overweight and obesity in adults [2]. To define and study the change of prevalence of overweight and obesity in each country, population-generated percentiles of BMI have been suggested by the IOTF. Therefore, the AGA collected
BMI data of more than 25,000 healthy German children from different regions in Germany in time period between 1985 and 1995 (fig. 2) [3]. Based on the generated percentiles and according to the suggestion of IOTF, a BMI > 90th percentile for age and gender was defined as overweight, a BMI $>97$ th percentile as obesity, and a BMI $>99.5$ th percentile as extreme obesity. Because BMI is not normally distributed in childhood, the LMS method to calculate standard deviation score BMI (BMI-SDS) as a measurement for the degree of overweight is available for these percentile. The LMS method summarizes the data in terms of three smooth agespecific curves called L (lambda), M (mu), and S (sigma) based on German population-specific data [3,4]. The $\mathrm{M}$ and $\mathrm{S}$ curves correspond to the median and coefficient of variation of body mass index for German children at each age and gender, whereas the L curve allows for the substantial agedependent skewness in the distribution of body mass index $[3,4]$. The assumption underlying the LMS method is that after Box-Cox power transformation the data at each age are normally distributed [4].

In a population-based study in more than 18,000 children and adolescents (KIGGS study [5]), the frequency of overweight and obesity was 8.5 and $6 \%$, respectively, based on the AGA percentiles in the year 2006. Since prevalence of obesity of $3 \%$ was expected based on the statistical definition and the percentiles of the AGA [3], this means that the frequency of obesity has doubled in the last 10 years in Germany. In Germany, there is a North-South divide of obesity prevalence (fig. 3) [6]. Adolescents are twice more frequently overweight as young children at school entry [6]. 


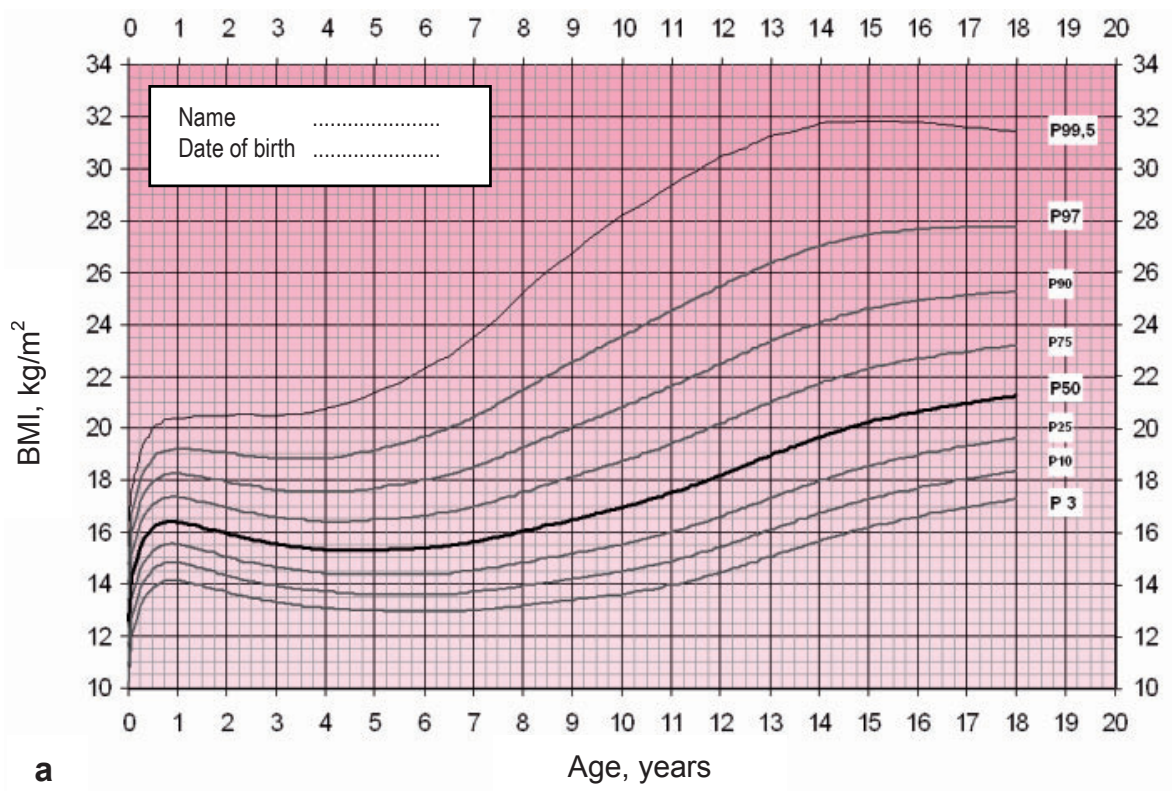

Fig. 2. Age- and gender-specific BMI percentiles to define overweight and obesity in Germany. a Girls ( $0-18$ years). b Boys ( $0-18$ years).

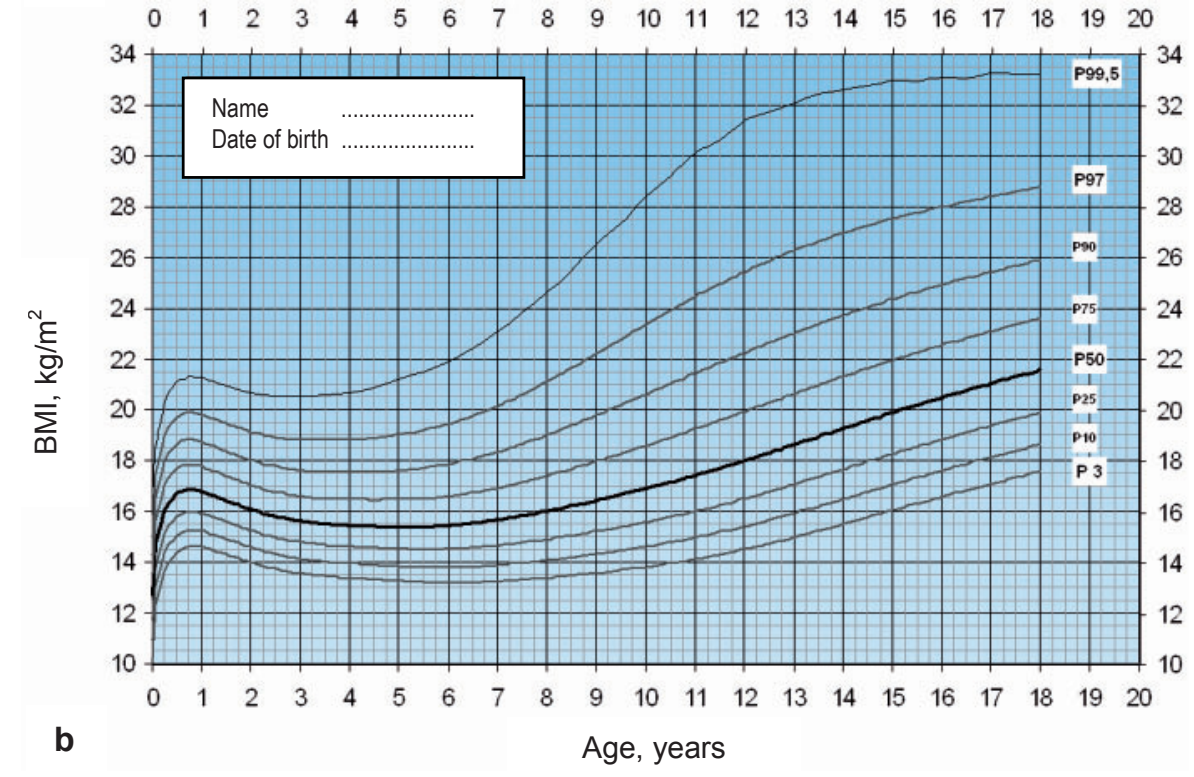

\section{Guidelines for Diagnostic Procedures and Treatment of Obesity}

Based on a consensus process of all AGA members and German experts in the field of obesity in childhood and adolescence, guidelines for diagnostic procedures and treatment of obesity were developed based on the AWMF criterions (see w.a-g-a.de) [7]. These guidelines are currently adapted to the four level of evidence-based medicine (S3 guidelines).

\section{Identifying All Therapy Centers for Obese Children and Adolescents in Germany}

Current care for overweight and obese children is controversially discussed, and few data are available comparing the process of care as well as the outcome among different institutions with different treatment approaches. The situation is even more heterogeneous in Germany, as in addition to longitudinal behavior-oriented outpatient care, a large number of children and adolescents are transferred to inpatient rehabilitation centers for a period of 4-6 weeks. In the year 2000, a structured questionnaire was sent to all member of the AGA, all inpatient and outpatient treatment centers for children, all public health institutions, and all health insurances in Germany $(\mathrm{n}=1,464)$. The response rate was high $(>60 \%)$. More than 200 inpatients and outpatient institutions could be identified treating obese children [8]. These institutions are published on the homepage of AGA (www.a-g-a.de). Nearly 10,000 obese children are treated in Germany yearly, most of them (>70\%) in inpatient rehabilitation centers [8]. The treatment experience was limited in 


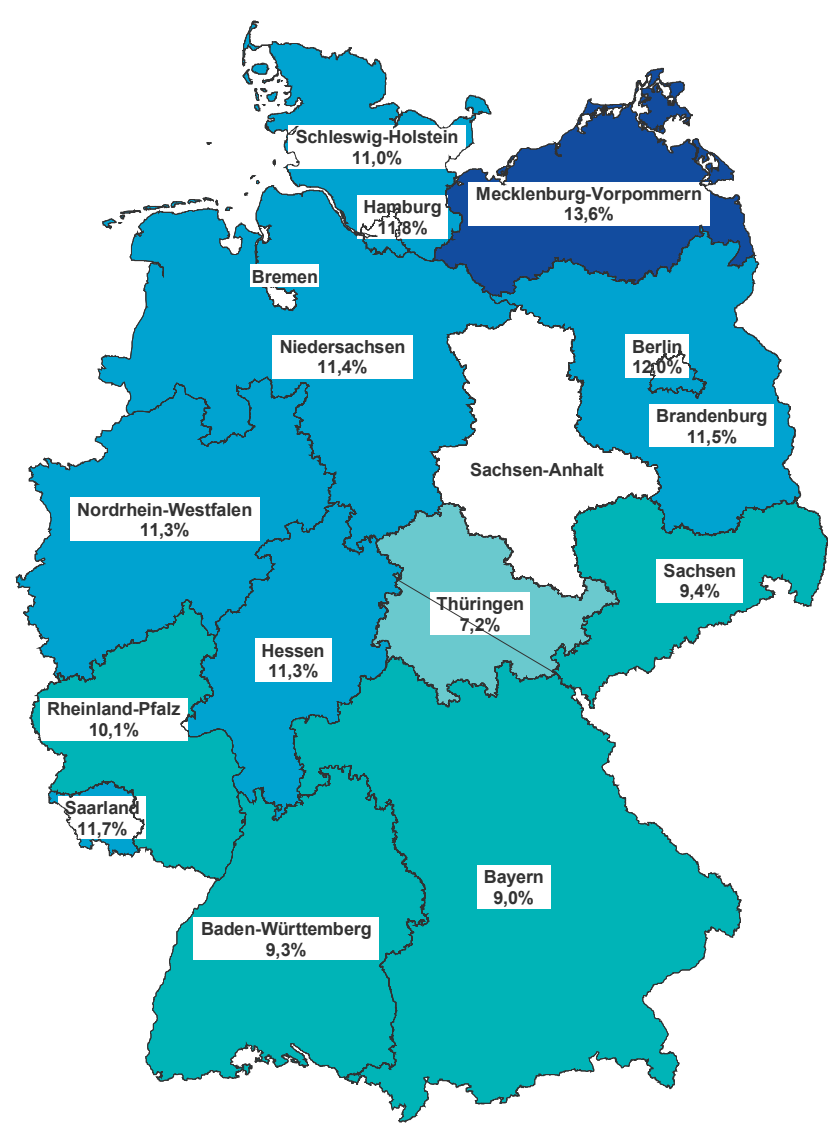

Fig. 3. Prevalence of overweight in children in different German regions.

most institutions, especially in outpatient treatment centers, and only 6 institutions have evaluated their treatment concept [8]. Therefore, objective data reflecting current care are urgently needed.

\section{Standardized Longitudinal Multicenter Documentation of Overweight and Obese Children}

Benchmarking among centers and center certification are established approaches to improve the quality of care and to reduce heterogeneity among care institutions. As a first step towards these goals, a software program for standardized documentation of relevant parameters was developed $[9,10]$. The documentation by the APV software includes the following parameters in a longitudinal way:

- anthropometric measurements (height, weight, waist),

- psychosocial risk factors (family, migration background, education),

- medical risk factors (hypertension, dyslipidemia, hyperglycemia, insulin resistance),

- intensity of intervention in several categories (medical care, dietary counseling, psychological interventions, sports therapy, all for patients and/or parents).

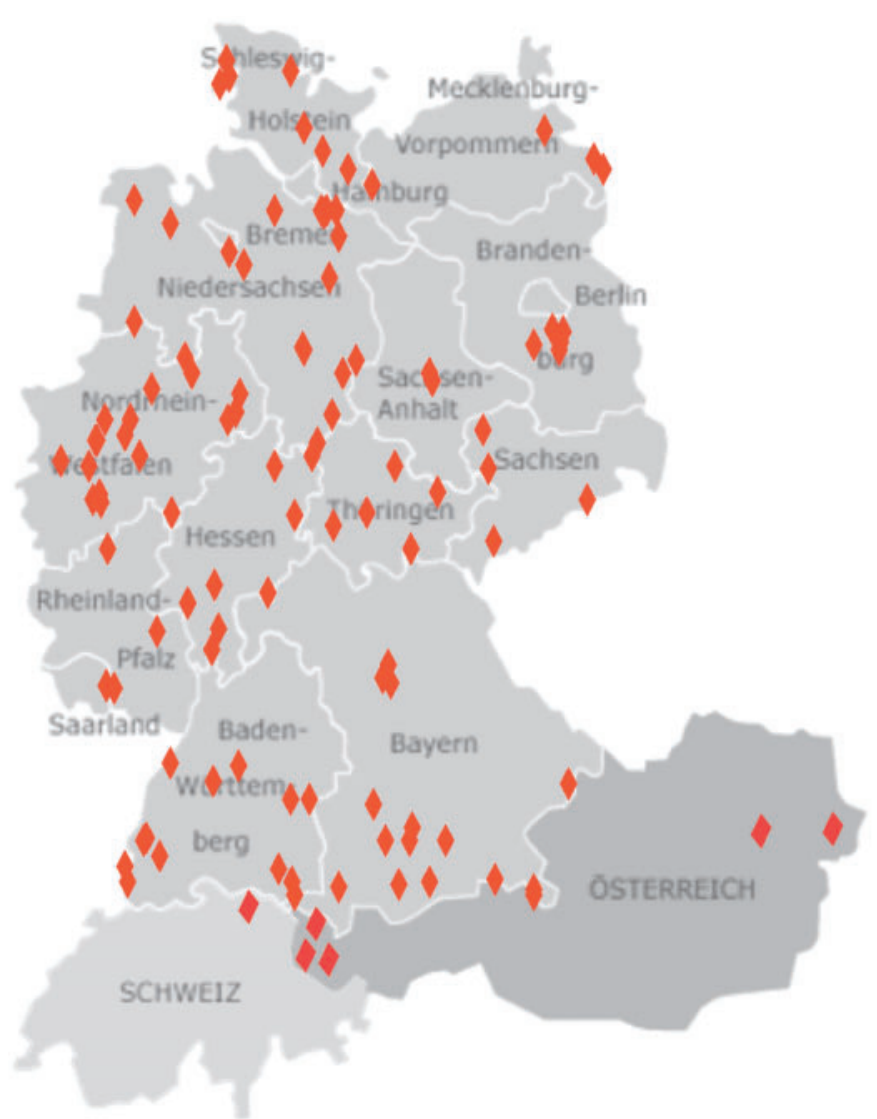

Fig. 4. Participating centers in the standardized longitudinal multicenter documentation (APV), 2007.

Additional, voluntary, more research-oriented parameters are - body composition (skinfold thickness, bioelectrical impedance analysis),

- physical fitness.

As an incentive for centers to use the software, software functionality includes e.g. automatic generation of medical reports for physicians, graphical and tabular representation of data, calculation of BMI-SDS LMS values, selection of patient groups according to multiple criteria including complex filtering, export function with open or anonymized data in three different formats to allow individual data analysis. A German trial version of the software can be downloaded from the APV website ( $w w w \cdot a-p$-v.de). The software can be installed on single computers, on institutional networks (intranet) as well as on an internet server with secure remote access. The latter option is suitable when patient education, training and medical care is provided simultaneously by multiple, geographically separated institutions. Figure 4 gives an overview of currently participating institutions in Germany, Switzerland, and Austria.

\section{Regular Benchmarking Reports}

Twice yearly, the participating centers transmit anonymized data from the APV software for combined analysis. A SAS 


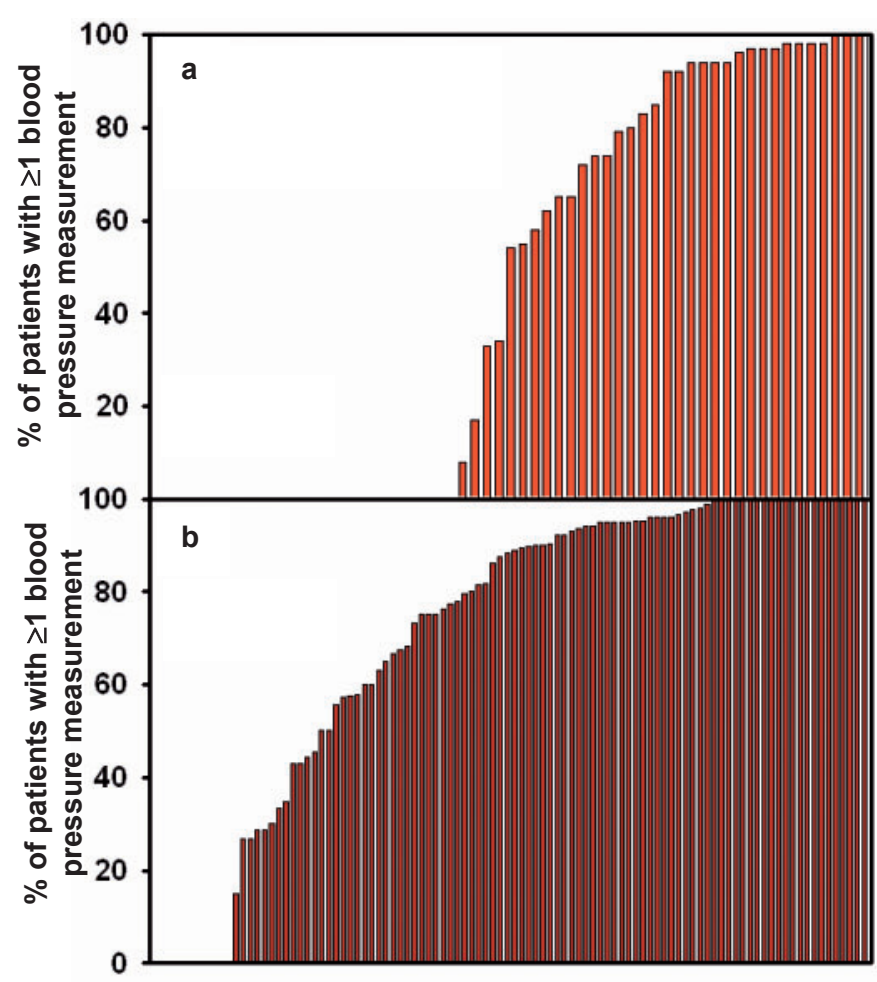

Treatment institutions

Fig. 5. Benchmarking comparison of completeness of blood pressure measurements in the years a 2004 and b 2007 among participating pediatric obesity care centers.

program has been developed which automatically generates a benchmarking report in a PDF format, which is transmitted back to the participating centers by e-mail. The report addresses the following areas:

- patient selection (age, gender, BMI at referral),

- completeness of diagnostic evaluation for co-morbidity,

- prevalence of co-morbidity,

- intensity of therapeutic intervention in several categories,

- outcome: short-term and long-term reduction of BMI, per protocol and intention-to-treat.

The reports are continuously improved, and new analyses were included with each benchmarking round. Thus, the software and the reports helps to improve quality of care of overweight children in Germany. For example, in the AGA guidelines blood pressure measurements are recommended in each overweight child. Figure 5 demonstrates how blood pressure measurements within the participating institutions increased between the years 2004 and 2007.

Figure 6 displays outcome data on BMI stability or reduction using an intention-to-treat approach. In several patients, a long-term success in overweight reduction was achieved, predominately in long-term outpatient programs. However, still the majority of the treated children has no long-term success. Therefore, quality of treatment has to be improved.

\section{Scientific Analyses Using the APV Data Pool}

In addition to benchmarking and quality management, anonymized patient records are aggregated and used for epidemiologic and scientific analyses. At present, the data pool comprises $1,192,004$ records from 41,842 patients $(26,017$ patients from rehabilitation/inpatient care and 15,825 patients from outpatient programs). One fifth of the patients are classified as overweight and $70 \%$ as obese (among the latter group $30 \%$ fall into the range of extreme obesity $(\mathrm{BMI}>99.5$ th percentile)). Analyses published so far exploring this database addressed the process of obesity care [9] and medical co-morbidities related to different degrees of obesity [11]. These analyses demonstrated that the frequencies of diagnostic procedures performed and documented were low (measurement of blood pressure, lipids and glucose metabolism 43, 40 and $21 \%$, respectively), while the presence of cardiovascular risk factors was high: $23 \%$ of the overweight children suffered from hypertension, $11 \%$ showed an increased cholesterol, $9 \%$ increased low-density lipoprotein cholesterol, $29 \%$ increased triglycerides, $11 \%$ decreased high-density lipoprotein cholesterol, and $6 \%$ an impaired glucose metabolism.

\section{Certificating of Therapeutic Institutions}

Since the treatment quality of obese children and adolescents is very heterogeneous in Germany, a certification process of treatment institutions was initiated in the year 2007. Based on the AGA guidelines and the national guidelines of health insurances and the German Federal Ministry of Health, criterions for structure, process, and result quality were determined (see a-g.a.de). All treatment institutions were checked for these criterions, and currently 16 institutions were certificated to fulfil all the criterions.

\section{Implementation of the BZgA Observation Study and the Trink Dich Fit Study}

The AGA also supports scientific projects in the field of pediatric obesity prevention and therapy. In the following, two studies initiated and supported by the AGA are briefly described exemplarily.

\section{BZgA Observation Study}

There are only few studies comparing process and outcome of obesity care among the many different care settings in Germany. However, such data are urgently needed to improve quality of care. In 2005, an observational study was initiated and financed by the Federal Center for Health Education (Bundeszentrale für gesundheitliche Aufklärung; $\mathrm{BZgA}$ ), comparing patient selection, process of care (evaluation of co-morbidity, type and intensity of education) as well as long-term outcome (BMI 1 year after completion of the 
Fig. 6. Intention-to-treat analysis comparing long-term effects of pediatric obesity programs in Germany/Austria. Only patients who entered a program at least 1 year prior to evaluation are included. Results are counted as success, if documented BMI-SDS at least 1 year after onset of treatment is equal to or less than BMI-SDS at treatment onset. Patients with higher BMI-SDS values in follow-up and patients lost to follow-up are counted as failure. Outpatient programs are represented by red bars, inpatient/rehabilitation programs by blue bars. APV data pool, October 2007.

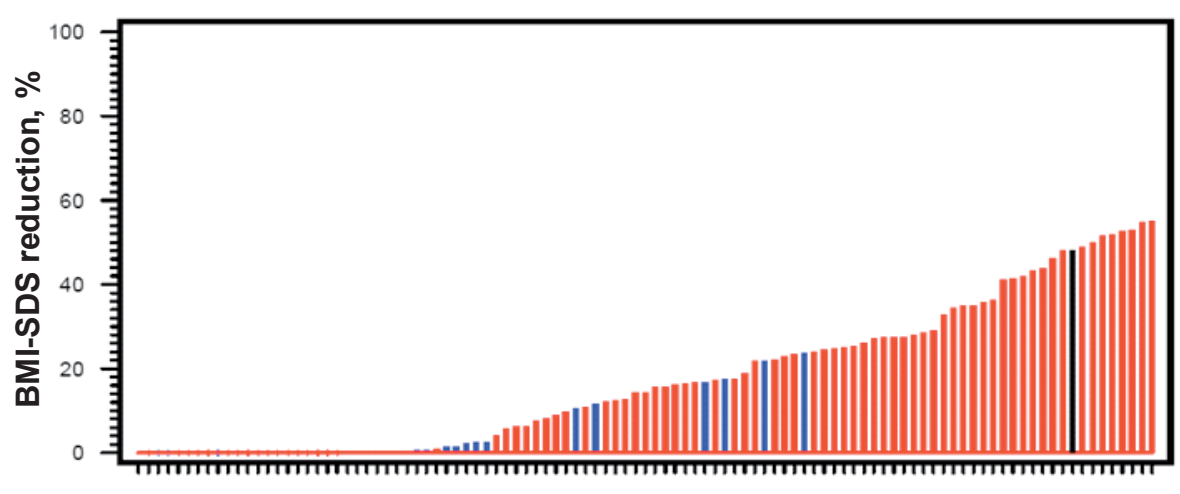

Treatment institutions program) of six classes of German intervention programs that vary in structural and quality criteria. Medical data (BMI, blood pressure, dyslipidemia) and an extensive questionnaire for both parents and children, addressing behavior, quality of life, family interaction and social aspects are combined. More than 2,000 patients have been recruited to the study. At present, most patients have completed therapy, and data on long-term response ( $>1$ year after onset of therapy) are collected.

\section{Trink-Dich Fit Study}

The prevention of overweight and obesity in children is one of the major challenges in medicine and public health today. Prompted by the positive effect on weight status in two recent smaller intervention trials focusing on decreasing caloric soft drink consumption [12, 13], a large randomized controlled cluster trial in primary schools in Germany with the sole intention of promoting water consumption by facilitating access to tap water was initiated. The hypothesis was that after intervention the prevalence and incidence of overweight would be significantly lower in the intervention than in the control group (as a consequence of consuming more water and less caloric beverages). The study population comprised 7- to 9year-old children (in the 2nd and 3rd grades) attending elementary schools in socially deprived neighborhoods in Germany. In total, 2,950 children (1,641 in the intervention group;
1,309 in the control group) were evaluated. In the intervention schools, a tap water dispenser was installed, and each child received an attractive water bottle. Three 2-hour lessons dealing with the need for water intake were administered additionally by the teachers. The control group did not receive any intervention. After the intervention, the prevalence and the incidence of overweight were significant lower in the intervention group than in the control group (23 versus $28 \%$ and 4 versus $6 \%$, respectively). In conclusion, this study demonstrated that a combination of environmental prevention strategy and education about water consumption without external support (parents, study personnel) was feasible, sustainable and effective in decreasing the number of overweight children. Furthermore, this encouraging outcome was achieved in children with socially deprived background who are at high risk of developing obesity.

\section{Future Projects of the German Working Group of Obesity in Childhood and Adolescence}

In the near future, the AGA plans to establish education centers of therapists in the field of obesity in childhood and adolescence. Furthermore, a network of scientific research centers will be developed. A grant of the German Federal Ministry of Education and Research is applied.

\section{References}

1 Ebbeling CA, Pawlak DB, Ludwig DS: Childhood obesity: public-health crisis, common sense cure. Lancet 2002;360:473-482.

2 Cole TJ, Bellizzi MC, Flegal KM, Dietz WH: Establishing a standard definition for child overweight and obesity worldwide: international survey. BMJ 2000;320:1-6.
3 Kromeyer-Hauschild K, Wabitsch M, Geller F, Ziegler A, Geiß HC, Hesse V, von Hippel A, Jaeger U, Johnsen D, Kiess W, Korte W, Kunze D, Menner K, Müller G, Müller JM, Niemann-Pilatus A, Remer T, Schaefer F, Wittchen HU, Zabransky S, Zellner K, Hebebrand J: Perzentile für den BodyMass-Index für das Kindes- und Jugendalter unter Heranziehung verschiedener deutscher Stichproben. Monatsschr Kinderheilkd 2001;149:807-818.
4 Cole TJ: The LMS method for constructing normalized growth standards. Eur J Clin Nutr 1990;44: 45-60.

5 Kurth BM, Schaffrath Rosario R: Die Verbreitung von Übergewicht und Adipositas bei Kindern und Jugendlichen. Bundesgesundheitsbl Gesundheitsforsch Gesundheitssch 2007;50:736-743. 
6 Moß A, Wabitsch M, Kromeyer-Hauschild K, Reinehr T, Kurth BM: Prävalenz von Übergewicht und Adipositas bei deutschen Einschulkindern. Bundesgesundheitsbl Gesundheitsforsch Gesundheitssch 2007;50:1424-1431.

7 Kunze D, Wabitsch M: Leitlinien der Arbeitsgemeinschaft Adipositas im Kindes- und Jugendalter. www.a-g-a.de.

8 Reinehr T, Wabitsch M: Strukturierte Erfassung der Therapieangebote für adipöse Kinder und Jugendliche - ein Projekt der Arbeitsgemeinschaft Adipositas im Kindes- und Jugendalter (AGA). Monatsschr Kinderheilkd 2003;151:757-761.
9 Reinehr T, Wabitsch M, Andler W, Beyer P, Böttner A, Chen-Stute A, Fromme C, Hampel O, Keller K, Kilian U, Kolbe H, Lob-Corzilius T, Marg W, Mayer H, Mohnike K, Oepen J, Povel C, Richter B, Riedinger N, Schauerte G, Schmahlfeldt G, Siegfried W, Smuda P, Stachow R, van EgmondFröhlich A, Weiten J, Wiegand S, Witte S, Zindel V, Holl RW: Medical care of obese children and adolescents. APV: a standardised multicentre documentation derived to study initial presentation and cardiovascular risk factors in patients transferred to specialised treatment institutions. Eur J Ped 2004; 163:308-312.

10 Lob-Corzilius T, Reinehr T, Wabitsch M, Holl RW: Software zur Adipositas-Verlaufsdokumentation 'APV'. Kinder- und Jugendarzt 2005;36:450-455.
11 L'Allemand D, Wiegand S, Müller J, Reinehr T, Wabitsch M, Widhalm K, Holl RW: Cardiovascular risk in 26008 European overweight children as established by a multicenter database. Obesity 2008 : (in press).

12 Ebbeling CB, Feldman HA, Osganian SK, Chomitz VR, Ellenbogen SJ, Ludwig DS: Effects of decreasing sugar-sweetened beverage consumption on body weight in adolescents: a randomized, controlled pilot study. Pediatrics 2006;117:673-680.

13 James J, Thomas P, Cavan D, Kerr D: Preventing childhood obesity by reducing consumption of carbonated drinks: cluster randomised controlled trial. BMJ 2004;328:1237. 